http://dx.doi.org/10.5007/2175-7968.2014v1n33p247

\title{
UVAS E CREPES: A PARÓDIA A PARTIR DA ARQUITEXTUALIDADE
}

\author{
Elizabeth Ramos* \\ Universidade Federal da Bahia
}

\begin{abstract}
Resumo: O presente artigo analisa a releitura feita por Os Simpsons do livro The Grapes of Wrath (As vinhas da ira - 1939) de John Steinbeck. Serão feitos comentários acerca da paródia como efeito de linguagem e o artigo também traz reflexões acerca da animação como um meio de redefinir, subverter e desafiar visões ortodoxas da experiência humana nas mais diversas culturas, neste caso, aplicadas especialmente à cultura norte-americana. Esse episódio, que visa parodiar aspectos do estilo de vida da família americana de classe média, satiriza aspectos daquela sociedade através de piadas implícitas e jogos de palavras. feitos para espectadores engajados. No referido episódio, The Crepes of Wrath, estabelece-se uma relação intertextual com o romance de John Steinbeck e, então, pode-se perguntar: De que forma se constrói tal relação de intertextualidade?

Palavras-chave: Intertextualidade. Os Simpsons. John Steinbeck.
\end{abstract}

\section{GRAPES AND CREPES: A PARODY BASED ON ARCHITEXTUALITY}

\begin{abstract}
This article analyzes the Simpsons' reframing of the book The Grapes of Wrath (1939) by John Steinbeck. Parody is discussed as an effect of language and the article also raises questions about animation as a means to redefine, subvert and challenge orthodox views of the human
\end{abstract}

\footnotetext{
* Doutorado em Letras e Linguística pela Universidade Federal da Bahia (2003). Pós-Doutorado pela Universidade de São Paulo (2014). Professor Adjunto IV do Instituto de Letras da Universidade Federal da Bahia. Salvador, Bahia, Brasil. E-mail: beth_ramos49@hotmail.com
} 
experience in different cultures and, in this case, especially applied to the North American culture. This Simpsons episode, which aims to parody the lifestyle of a North American middle class family, satirizes aspects of that society through subtle jokes and puns. In the referred episode, The Crepes of Wrath, there is an intertextual relationship with a novel by John Steinbeck and then it is possible to ask: How is such intertextual relationship constructed?

Keywords: Intertextuality. The Simpsons. John Steinbeck.

Nas traduções intersemióticas, não raro prevalece a dialética platônica da rivalidade, em que as traduções, por não atingirem o grau de 'pureza' da obra em que se basearam, costumam receber do público um valor negativo, cabendo aos seus 'originais', o 'prêmio' do valor positivo. Essa constatação sugere que, quanto maior o nível de canonicidade e sacralização de uma obra artística, e quanto maior a popularidade do meio de comunicação de massa que acolhe sua tradução, menor será o valor do novo texto.

O caráter de transgressão, simplificação e empobrecimento atribuído ao texto traduzido faz-se ainda mais significativo, quando se trata de uma relação de arquitextualidade construída entre um filme de animação e um romance canônico. A esse tipo de apropriação e recriação é, não raro, atribuída uma dupla subversão: como se não bastasse o desvio do conteúdo, o texto é convertido a um simples desenho animado.

No entanto, no início no século XX, já se reconhecia que a animação poderia adquirir status de veículo estético e economicamente viável, distinto do contexto do cinema ortodoxo. Ícone na animação experimental, o britânico Norman McLaren (1914-1987), encontrou junto ao National Film Board do governo do Canadá, na década de 1940, as condições para desenvolver suas técnicas e pesquisas. Com motivação e criatividade, foi responsável pela criação de animações inovadoras, que relacionavam cor, imagem, ritmo e som, possíveis somente no desenho animado. Para ele, a animação "não é a arte de desenhos em movimento, mas a arte de movimentos que são desenhados. O que acontece entre cada frame é mais 
importante do que acontece em cada frame" (LUCENA JÚNIOR, 2005, p. 93, grifo do autor).

Anos depois, os integrantes da Escola de Zagreb, na antiga Iugoslávia da década de 70, enfatizavam que a animação dava vida ao desenho, transformando realidades, ao invés de copiá-las. A partir desse ponto de vista, podemos então afirmar que a animação não está interessada em copiar coisas, fatos e escritos, nas suas formas e aspectos. O que interessa a esse tipo de arte é o que as imagens podem significar. Estamos, portanto, diante da própria noção de simulacro, uma vez que "o ilimitado, é a [sua] matéria, na medida em que se furta à ação da Idéia, na medida em que contesta ao mesmo tempo tanto o modelo como a cópia" (DELEUZE, 2006, p.2).

O cartunista de animação Jan Svankmajer (1934) refere-se à sua experiência:

\begin{abstract}
A animação me permite dar poderes mágicos às coisas, nos meus filmes. Movimento muitos objetos, objetos reais. De repente, o contato diário, a que as pessoas estão habituadas, adquire nova dimensão e, dessa maneira, surge a dúvida sobre a realidade. Em outras palavras, utilizo a animação como meio de subversão. (WELLS, 2000, p. 238).
\end{abstract}

Para Svankmajer a animação pode redefinir o dia-a-dia, subverter nossas noções de realidade e desafiar as visões ortodoxas sobre a nossa experiência, ou seja, pode confirmar o que o poeta Samuel Coleridge chamou de suspensão da descrença (suspension of disbelief), na medida em que, ao assistir ao filme animado, o espectador interrompe a desconfiança acerca da improbabilidade, por exemplo, dos desafios às leis da gravidade, de coisas inanimadas tornarem-se vivas, das novas relações espaço-tempo.

Sendo a animação um meio de subversão, parece claro associá-la à paródia - "uma ode que perverte o sentido de outra ode (grego: para-ode)"(SANT'ANNA, 2003, p.12) - transposição criati- 
va, resultante da necessária submersão crítica do tradutor (no caso, o criador do desenho animado) na obra ou no assunto a ser apropriado e recriado intersemioticamente. A associação desvela a voz do simulacro, fazendo-se construir por meio de um juízo de valor, resultante de um processo de interpretação, que, propositadamente, foge da modelagem.

[...] a paródia, por estar do lado do novo e do diferente, é sempre inauguradora de um novo paradigma [...] constrói a evolução de um discurso, de uma linguagem, sintagmaticamente [...] é uma descontinuidade [...]. Falar de paródia é falar de intertextualidade das diferenças. (SANT'ANNA, 2003, p. 27-8).

A contemporaneidade assiste, com frequência cada vez mais acentuada, à presença da paródia como efeito de linguagem em diferentes artes, talvez como contraponto e fonte de reflexão à força da cultura da mídia através da qual a sociedade pode construir a sua identidade, seu sentido de 'nós', modelando valores, opiniões políticas, comportamentos, legitimando poderes.

Na televisão, o seriado Os Simpsons ilustra nosso ponto de vista de que a animação pode redefinir, subverter e desafiar visões ortodoxas sobre a experiência humana, particularmente, quando consideramos o caráter hegemônico dos Estados Unidos da América.

O seriado Os Simpsons tem como proposta parodiar aspectos do estilo de vida da classe média dos Estados Unidos, satirizando vários aspectos da condição humana, da política e da cultura daquele país, da sociedade como um todo, e até mesmo da televisão. Segundo o próprio Groening, trata-se de um show cheio de detalhes, piadas implícitas e jogos de palavras, feito para espectadores engajados (GROENING, 1997, p. 9).

Entre os cerca de trezentos e setenta e oito episódios, divididos em dezessete temporadas, encontra-se o de número 11, na primeira 
temporada, intitulado The Crepes of Wrath, que foi ao ar, pela primeira vez, em 15 de abril de 1990. O título do episódio, ao tempo em que alude à iguaria francesa, constrói um padrão de intertextualidade com o título do romance de John Steinbeck (1992), The Grapes of Wrath, de $1939^{1}$, padrão esse conhecido, na taxonomia de Gerard Genette, como arquitextualidade.

O título da animação surpreende e causa certo estranhamento ao espectador tradicional, conhecedor da literatura norte-americana e da proposta de Groening. Como parodiar uma obra que traz para as páginas literárias a reconstrução da grande tragédia dos anos 30, que abalou as estruturas da nação norte-americana, levando milhares de trabalhadores a perderem seus empregos, negócios, casas e terras nos Estados Unidos? Como satirizar uma década em que famílias inteiras, amontoadas entre seus poucos pertences nas carrocerias de calhambeques, abandonavam suas fazendas em ruínas, rumo a cidades assoladas pelo desemprego, agrupando-se em campos migratórios, pressionadas por um cruel processo de migração forçada?

O romance de Steinbeck reconstrói algo pior do que a ameaça da fome: o choque do desemprego, que afetava profundamente o estado de espírito dos migrantes. Homens, antes acostumados a sustentar a família, perdiam o emprego, seus bens e a esperança de integrar, novamente, o mercado de trabalho. Alguns se viam obrigados a deixar o orgulho de lado e a aceitar qualquer tipo de tarefa, em consonância com a noção vitoriana de que o homem sem trabalho é um vagabundo, um fracassado, um peso para a sociedade. Outros tinham a autoestima abalada pelas inúmeras e infrutíferas entrevistas, quadro que instaurava a nova configuração familiar: o pai de família desempregado e frustrado, sem saída, tornava-se um radical, ou desistia de tudo e caía em profundo estado de apatia, que, não raro, culminava em loucura ou suicídio. Cabia, portanto, à mulher manter o equilíbrio da família.

Num sentido global, o maior impacto social da Depressão parece ter sido a perda quase total da confiança que o cidadão comum 
tinha no sistema, e que caracterizara a nação americana desde os tempos da revolução. $\mathrm{O}$ homem perdeu a dignidade e o respeito por si próprio. Até mesmo os que tiveram mais sorte, e conseguiram liquidar suas dívidas, durante aqueles anos amargos, perderam a fé nas promessas do sistema capitalista, nos líderes políticos e heróis que pareciam impotentes diante da catástrofe do colapso econômico. De repente, a Constituição parecia um mero documento romântico, antigo e superado. A desconfiança nas leis propiciou o surgimento de gangsters, e o descrédito nas instituições financeiras resultou na quebra dos bancos e na destruição do capital de milhares de indivíduos.

Os escritores norte-americanos impuseram-se a tarefa de contar a tragédia da nação transformada, convertendo a década de 30 num fértil período de produção literária rica em crítica social, após o esfacelamento dos sonhos construídos nos anos 20. Por outro lado, o cinema hollywoodiano, com produções extravagantes como Gold Diggers of 1933, continuava de pé, buscando mostrar que a crise era transitória, e que o sonho americano iria prosseguir depois do vendaval econômico. O teatro, menos otimista, procurava encenar o sentido da crise, defendendo a necessidade de uma ação política. Jovens dramaturgos como Tenessee Williams, em Nova Orleans, Arthur Miller, em Michigan, envolveram-se com o teatro radical e se tornaram mais tarde, nos anos pós-guerra, a linha mestra da Broadway.

Muito embora, o presidente Franklin Roosevelt, sob a batuta do economista inglês John Keynes, tenha assinado o New Deal, com o objetivo de aumentar o poder aquisitivo dos então 120 milhões de habitantes, dar socorro aos desempregados, aumentar o rendimento dos agricultores e construir obras públicas, o que realmente pôs fim à Depressão não foi a solidariedade humana, mas a Segunda Grande Guerra, período em que muitos dos migrantes encontraram emprego como operários de estaleiros e fábricas de armamentos e munições.

O locus do grande romance de John Steinbeck é, portanto, um país social e economicamente injusto, estando o enredo alicerçado na experiência vivida pelo autor, na condição de repórter enviado pelo San Francisco News para cobrir os horrores vividos pelos 
migrantes do Dust Bowl nos Hoovervilles ${ }^{2}$ e Little Oklahomas da Califórnia rural, em 1936. A ficção leva o leitor a observar o fim de um sonho, para o qual a única salvação seria o que acreditamos constituir a grande ou fundamental metáfora da obra: a unidade do ser humano. This is the beginning: from 'I' to 'we' [...] a fella ain't no good alone $e^{3}$. Assim, a tragédia de The Grapes of Wrath é o esgarçamento da família ao longo de um penoso processo migratório, forçado pelas transformações econômicas e sociais ocorridas na região do Dust Bowl. Em estilo bíblico, buscando a recuperação de sua identidade, a família migra através da Rota 66 - "the Main Street of America" (a Rua Principal da América) - para a Califórnia, a fértil Terra Prometida, povoada por gente emocional e fisicamente aniquilada pela fome e pelo medo, com sua identidade desintegrada, terreno fértil para o despertar da ira.

A ficção literária dos Estados Unidos, no período da Depressão, tem, entre outros, o papel de revelar a fragilidade dos sonhos e valores do país, dando ao leitor uma nova visão de mundo, ao tempo em que expressa o engajamento do autor. Nada mais atual.

$\mathrm{O}$ episódio The Crepes of Wrath não pretende repetir, dar continuidade ou reforçar o romance de John Steinbeck. Não pretende, tampouco, assumir em relação à obra escrita, o que Affonso Romano de Sant'Anna chama de 'intertextualidade da semelhança'. É uma nova obra re-significada, que faz uso de outras linguagens - a animação e a paródia - a partir de um outro contexto de enunciação, embora se construa sobre uma relação intertextual e, particularmente, arquitextual com um texto matricial. O episódio dos Simpsons contesta, simultaneamente, o modelo e a cópia, isto é, subverte tanto o 'original' do romancista norte-americano, quanto, por exemplo, a adaptação cinematógrafica dos anos 40, dirigida por Darryk F. Zanuck - que tenta se aproximar do romance, apesar da decisão lamentável de eliminar o belíssimo episódio final da obra escrita.

A animação de Matt Groening, embora mantenha com a anterioridade uma ligação no âmbito da arquitextualidade, isto é, construa com o romance de Steinbeck uma relação intertextual a 
partir do próprio título, não resulta naquilo que normalmente consideramos adaptação. The Crepes of Wrath constitui, claramente, um exercício de suplemento, de atualização crítica, refletindo um movimento da significação, acrescentando algo "flutuante porque vem substituir, suprir uma falta do lado do significado" (DERRIDA, 1971, p. 245).

Assim, o processo de re-significação crítica e de auto-reflexividade, construído através da linguagem paródica na animação, não pretende ser uma paráfrase de The Grapes of Wrath. "O que é notável na paródia moderna é o seu âmbito intencional do irônico e jocoso ao desdenhoso ridicularizador" (HUTCHEON, 1985, p. 17). Na condição assumidamente de simulacro, contesta, desloca, atualiza e não abre mão da sua voz. Não apaga seu ponto de vista, nem se torna subserviente. Desvia, é infiel, transgride, não se submete ao fundamento, constrói seu próprio juízo de valor, rompe com a estabilidade e a hierarquização da arte, destrói a unicidade do 'original' com as diferentes possibilidades do olhar, trazendo as marcas de seus criadores que, embora intérpretes de um texto anterior, são indivíduos críticos, assujeitados por sua história, pelo seu tempo, pelo seu lugar de fala.

O episódio em animação contrapõe o país construído no romance de Steinbeck aos Estados Unidos da contemporaneidade, trazendo à tona, através da ironia, o olhar provinciano em relação ao resto do mundo, garantindo, ao filme, acentuada função crítica. A migração forçada, a errância dos anos 30, dá lugar ao intercâmbio de estudantes: um deles, o albanês Adil, recebido pela família Simpson, tipicamente norte-americana e extremamente hospitaleira. O rapaz, no entanto, tem como objetivo espionar segredos sobre o enriquecimento de urânio nas usinas norte-americanas, onde trabalham cidadãos ingênuos, entre os quais se inclui Homer Simpson. Springfield, a nova cidade de residência do estudante albanês, dispõe de aeroporto internacional com a possibilidade de pouso e decolagem de vôos diretos para Tirana e Paris, destino do adolescente Bart Simpson, que será maltratado e explorado por dois 
bandidos franceses que o hospedam em condições subumanas. Na França, as uvas retiradas cuidadosamente das vinhas serão pisadas pelo humilhado Bart, que, então, manifestará sua ira, e terminará aclamado como herói, por denunciar a ilegalidade da fabricação do vinho doméstico, que inclui na sua composição substâncias que impedem o congelamento do produto, a exemplo do que aconteceu na Áustria, no início dos anos 90, no século XX.

A leitura do texto literário e do texto animado permite-nos constatar o desaparecimento do tom trágico da obra escrita, com o qual a paródia e a ironia mantêm as mais ambivalentes relações. $O$ vínculo com o texto matricial é lembrado no título do episódio e no discurso crítico deslocado a outro lugar de fala, através de uma outra linguagem, temperada por humor "abolindo-se toda profundidade e altura" (DELEUZE, 2006, p. 143), estando precisamente na re-significação as possibilidades de uma variedade de interpretações e reflexões a respeito de muitas das questões atinentes à contemporaneidade. Se concordarmos com Linda Hutcheon, quando afirma que "a ironia é a principal estratégia retórica utilizada pelo gênero" (1985, p. 37), claro está que a animação desenvolve uma atualização e uma releitura crítica intersemiótica da obra de John Steinbeck.

O episódio deixa de ser um produto degradado, empobrecido, menos nobre e desrespeitoso, a ser consumido por espectadores não letrados, para tornar-se vivo e atual, através do trabalho de apropriação, interpretação e recriação de uma nova arte, que possibilitará outras interpretações por parte dos espectadores do texto em animação, numa clara demonstração de que o intérprete constitui o princípio da interpretação e de que, portanto, esta não poderá jamais ser concluída, pois haverá sempre possibilidades de outros arranjos, de outras interpretações.

No caso, ainda que o espectador não conheça o romance de Steinbeck, e não seja capaz de estabelecer a relação de intertextualidade exigida para o reconhecimento da paródia em relação à obra escrita, poderá construir a crítica à visão hegemônica dos Estados Unidos em relação ao resto do mundo. O espectador será 
confrontado com estereótipos culturais que, muitas vezes, alicerçam crenças e ideologias com relação ao Outro - o albanês espião $x$ o norte-americano hospitaleiro e ingênuo construídos no rastro da Guerra Fria; o francês esperto e aproveitador $x$ o herói norte-americano, que obrigado a dormir no chão e transformado em mão de obra escrava nos vinhedos franceses, denuncia as práticas ilegais dos produtores de vinho.

Alguns extratos retirados da animação podem ilustrar a construção da paródia crítica dessas dualidades. Tal é o caso da cena em que Homer Simpson apresenta a Adil os donuts, guloseima típica dos Estados Unidos, semelhante ao nosso sonho: "See these? American donuts. Glazed, powdered, and raspeberry-filled. Now, how's that for freedom of choice?" 4

Conversando com a família sobre Adil, Homer Simpson faz a seguinte declaração:

You may find his accent peculiar. Certain aspects of his culture may seem absurd, perhaps even offensive. But I urge you all to give little Adil the benefit of the doubt. In this way, and only in this way, can we hope to better understand our backward neighbors throughout the world..$^{5}$ (grifo meu)

O episódio traz clichês utilizados no âmbito da Guerra Fria, para reforçar o tom paródico da animação:

Adil: How can you defend a country where five percent of the people control ninety-five percent of the wealth?

Lisa: I'm defending a country where people can think and act and worship any way they want!

Adil: Cannot!

Lisa: Can too!

Adil: Cannot!

Lisa: Can too!

Homer: Please, please kids, stop fighting. Maybe Lisa's 
right about America being the land of opportunity and maybe Adil has a point about the machinery of capitalism being oiled with the blood of the workers. ${ }^{6}$

Nesse sentido, a paródia adota, também, o papel de sátira, ridicularizando os preconceitos e loucuras da Humanidade, que, na animação em questão, se restringe, particularmente, ao país natal do seu idealizador e à tolice da Guerra Fria.

Assim, The Crepes of Wrath, partindo de uma relação arquitextual com o título do romance The Grapes of Wrath, inaugura um novo paradigma, instaura a intertextualidade das diferenças e dá nova dimensão crítica àquela anteriormente levantada no romance de John Steinbeck, subvertendo-a e, simultaneamente, redefinindo a fragilidade dos sonhos e valores de uma nação. Seu trânsito engajado e intencional do irônico ao jocoso, do desdenhoso ao ridicularizador, desafia os estereótipos que opõem o 'nós' ao Outro, levando o espectador a concluir que ainda não se conseguiu chegar ao começo proposto por Steinbeck: do 'eu' para o 'nós'. O sujeito continua só.

\section{Notas}

1. Romance traduzido no Brasil sob o título As vinhas da ira.

2. Dust bowl foi como se tornou conhecida a região do meio sul dos Estados Unidos, assolada pela seca na década de 30 , que, dado o tipo de terreno, formou uma espécie de grande "tigela de poeira". Hoovervilles eram os acampamentos construídos pelo governo para abrigar os migrantes na Califórnia. O nome homenageia o então Presidente da República Herbert Hoover, que governou de 1929 a 1933. 
3. Minha tradução: "É assim que começa: do 'eu' ao 'nós' [...] um sujeito não vale nada sozinho".

4. Minha tradução: "Está vendo isso aqui? Donuts americanas. Cobertas de glacê, polvilhadas e recheadas de frutas vermelhas. E aí, o que você me diz de toda essa liberdade de escolha?"

5. Minha tradução: "Vocês podem achar o sotaque dele estranho. Alguns aspectos da sua cultura podem parecer absurdos, e talvez até ofensivos. Mas peço que dêem ao pequeno Adil o privilégio da dúvida. Assim, e só assim, poderemos compreender melhor nossos vizinhos atrasados pelo mundo afora”.

6. Minha tradução: "Adil: 'Como é que você pode defender um país em que 5\% do povo controlam $95 \%$ da riqueza?' Lisa: 'Eu defendo um país onde o povo pode pensar e agir e reverenciar qualquer coisa que quiser.' Adil: 'Não pode, não!' Lisa: 'Pode, sim.' Adil: 'Não pode, não!' Lisa: 'Pode, sim.' Homer: 'Por favor, crianças. Parem de brigar. Talvez Lisa tenha razão em dizer que a América é a terra da oportunidade, e talvez Adil tenha suas razões para dizer que o capitalismo é azeitado com o sangue dos trabalhadores.'”

\section{Referências}

DERRIDA, Jacques. A escritura e a diferença. Tradução de Maria Beatriz Marques Nizza da Silva. São Paulo: Perspectiva, 1971. (Coleção Debates).

DELEUZE, Gilles. Lógica do sentido. Tradução de Luiz Roberto Salinas Fortes. São Paulo: Perspectiva, 2006. p. 2.

GROENING, Matt. The Simpsons: a complete guide to our favorite family. Nova York: Harper Perennial, 1997. 
HUTCHEON, Linda. Uma teoria da paródia. Tradução Teresa Louro Pérez. Lisboa: Edições 70, 1985.

LUCENA JÚNIOR, Alberto. Arte da animação: técnica e estética através da história. 2. ed. São Paulo: Editora Senac, 2005.

SANT'ANNA, Affonso Romano de. Paródia, Paráfrase \& Cia. 7. ed. São Paulo: Ática, 2003.

STEINBECK, John. The Grapes of Wrath. Nova York: Penguin Books, 1992.

WELLS, Paul. Animation: forms and meanings. In: NELMES, Jill (Ed.). An introduction to filmstudies. London; New York: Routledge, 2000, p. 238.

Recebido em: 15/01/2014 Aceito em: 29/04/2014 
